\title{
Photocatalytic study of organosilane-modified zinc oxide nanoparticles
}

\author{
Aurel TĂBĂCARU, ${ }^{*}$ Mariana BUȘILĂ, Viorica (GHISMAN) PLEȘCAN and Viorica MUȘAT* \\ Center of Nanostructures and Functional Materials - CNMF, Faculty of Engineering, "Dunărea de Jos" \\ University of Galați, 111 Domneasca Street, 800201, Galați, Romania
}

\begin{abstract}
In our recent studies, we have investigated the tunability of optical properties of zinc oxide nanoparticles (ZnO NPs) through surface modification with organosilane surfactants. In the present paper, the effect of ZnO NPs modified with variable amount of 3-(trimethoxysilyl)propylmethacrylate (MPS) surfactant was investigated toward the photocatalytic degradation of methylene blue (MB), using two different UV light sources emitting at $254 \mathrm{~nm}$ and $365 \mathrm{~nm}$. While the maximum photodegradation efficiency of $63 \%$ was reached by $\mathrm{ZnO}$ NPs loaded with the highest concentration of MPS upon exposure at $254 \mathrm{~nm}$, in the case of UV exposure at $365 \mathrm{~nm}$ an opposite photodegradation trend was observed. Actually, a significant photodegradation efficiency of $95 \%$ was recorded by the unmodified $\mathrm{ZnO}$, followed by $\mathrm{ZnO}$ NPs modified with $2 \%$ MPS for which the photodegradation efficiency amounted to $80 \%$, thus highlighting their best photocatalytic performance.
\end{abstract}

Keywords: zinc oxide nanoparticles, photocatalysis, photodegradation efficiency, methylene blue.

\section{Introduction}

Zinc oxide is an n-type II-VI semiconductor with a wide band gap of $3.37 \mathrm{eV}$ [1], a high exciton binding energy of $60 \mathrm{meV}$ at room temperature [2], good transparency, high electron mobility and roomtemperature photoluminescence [3]. These features make this material very favorable for emerging applications in, e.g., optoelectronics [4], UV lasers and photodetectors [5], solar cells [6], thin film transistors [7], gas sensing [8], catalysis [9], cell labeling [10], and even in medical field as antibacterial agents [11] or in naval area as antifouling coatings [12].

One major problem of global concern is related to wastewater treatment, which could be reasonably solved by means of photocatalysis. This recent technology has been adopted as a more efficient and alternative way to activated carbon and biological methods for wastewater treatment. Nanocrystalline $\mathrm{TiO}_{2}$ and $\mathrm{ZnO}$ semiconductors were found to be the most attractive candidates for wastewater treatment, and are well known for their photocatalytic activity, chemical stability, lower cost, easy availability, and strong oxidative capacity $[13,14]$.

The utilization of such metal oxide based semiconductors materials for the degradation and complete mineralization of a wide range of organic compounds, such as dyes, phenols and pharmaceutical drugs, has already produced several promising results [15-17]. Due to the increasing demands for $\mathrm{TiO}_{2}$ in the last few years, its commercialization value has raised, thus exceeding the value of $\mathrm{ZnO}$ [18], and therefore, the latter has been chosen as a more suitable alternative resource for $\mathrm{TiO}_{2}$ in terms of efficiency, cost-effectiveness and environment-friendliness. Actually, due to higher quantum efficiency and low cost of production, $\mathrm{ZnO}$ is considered to possess a more efficient photocatalytic activity compared to $\mathrm{TiO}_{2}$, though having comparable intrinsic band gap energy $[19,20]$.

A crucial shortcoming that arises when adopting $\mathrm{ZnO}$ NPs in photocatalysis is their tendency to agglomerate due to large surface area and high surface energy. This makes more difficult their utilization in the form of very small nanoparticles, and therefore, it is of demanding importance to control their particles size and surface properties. In this regard, recent researches have revealed on the improvement of photocatalytic activity of $\mathrm{ZnO}$ NPs by means of their modification through cationic or anionic doping or by means of adding metals or nonmetals [21-23]. Doping $\mathrm{ZnO}$ with coinage metals such as silver or gold has shown enhanced photocatalytic activity of the resulting $\mathrm{ZnO}$ nanocomposites due to improved charge separation and reduction in electron-hole recombination [2426].

In our recent investigations, $\mathrm{ZnO}$ NPs were modified with organosilane surfactants such as 3(trimethoxysilyl)propylmethacrylate (MPS) [27] and vinyltrimethoxysilane (VTMS) [28], or with a diquaternary salt of bis(pyridinium) such as N,N'- 
di(p-methoxyphenacyl)-1,2-bis(4-pyridinium)ethane (DSB) [29], and the influence of particles size on the optical properties was studied. In the present contribution, we sought to study the photocatalytic activity, though very less explored, of organomodified $\mathrm{ZnO}$ NPs. Therefore, the effect of $\mathrm{ZnO}$ NPs modified with variable amounts of MPS, with different sizes, was investigated toward the photocatalytic degradation of methylene blue (MB) in aqueous solution, using two different UV light sources emitting at $254 \mathrm{~nm}$ and $365 \mathrm{~nm}$.

\section{Experimental}

\subsection{Synthesis of organosilane-modified $\mathrm{ZnO} N P s$}

The organosilane-modified $\mathrm{ZnO}$ NPs were prepared according to the precipitation method reported in the literature [27]. The obtained samples are hereafter labeled with $\mathrm{ZnO}$ for the unmodified nanoparticles, and $\mathrm{ZnO}-\mathrm{MPS}-\mathrm{x} \%$ for $\mathrm{ZnO} \mathrm{NPs}$ modified with 2, 5 and $10 \%$ MPS, respectively.

\subsection{Nanoparticles characterization}

The X-ray powder diffraction (XRD) patterns of the obtained nanoparticles were recorded on unoriented ground powders with a DRON-3 diffractometer with a Co $\mathrm{K}_{\alpha}(\lambda=1.79 \AA)$ radiation, between 10 and $60^{\circ} 2 \theta$ degrees with a step size of $0.02^{\circ}$. The diffractograms represented in Fig. 1 were however obtained after applying the conversion factors from $\mathrm{Co} \mathrm{K}_{\alpha}$ to $\mathrm{Cu} \mathrm{K}$ radiation of the $2 \theta$ values. The average crystallite size $(L)$ of synthesized $\mathrm{ZnO}$ NPs was estimated by applying the Debye-Scherrer's Eq. (1) [30]:

$$
B(2 \theta)=\frac{K \cdot \lambda}{L \cdot \cos \theta}
$$

where $B$ is the full width at half the maximum intensity (FWHM), $\lambda$ is the X-ray wavelength, $\theta$ is the diffraction angle and $K$ is the Scherrer's constant whose value for spherical particles is 0.89 [31].

Scanning electron microscopy (SEM) images were collected on a Quanta 200 scanning electron microscope operating at $15 \mathrm{kV}$. Specimens were prepared by dispersing the samples by sonication in methanol and by depositing few drops of the suspensions on carbon-coated grids.

\subsection{Photocatalytic measurements}

The photocatalytic activity of $\mathrm{ZnO}$ NPs was evaluated through the bleaching of methylene blue (MB) aqueous solution $(20 \mathrm{~mL}, 0.1 \%)$ in the presence of $0.05 \mathrm{~g}$ powder of investigated nanoparticles, under UV illumination at both $254 \mathrm{~nm}$ and $365 \mathrm{~nm}$ for $60 \mathrm{~min}$.

The bleaching of MB aqueous solution was quantitatively measured by UV-Vis absorption spectra performed with a Microplate reader with fluorescence spectrometer Infinite 200 PRO NanoQuant (Tecan, Switzerland), in the 400-800 nm range.

The photocatalytic activity of the prepared $\mathrm{ZnO}$ photocatalysts was quantitatively evaluated by determining the photodegradation efficiency $(\eta \%)$ of methylene blue with Eq. (2):

$$
\eta=\frac{A_{0}-A}{A_{0}} \cdot 100
$$

where $A_{0}$ is the absorbance of the dye-containing solutions before UV illumination and $A$ is the absorbance of the same solutions after UV illumination.

\section{Results and Discussions}

3.1. Morpho-structural characterization of ZnO NPs

The XRPD patterns of all samples (Fig. 1) show the three main diffraction peaks located in the $30-$ $40^{\circ} 2 \theta$ range, assignable to the (100), (002) and (101) planes that are specific for zinc oxide wurtzite structure [32]. Worthy of note, the diffraction pattern of unmodified $\mathrm{ZnO}$ NPs shows well resolved reflections, while a broadening of the diffraction peaks are observed in the case of MPS-modified $\mathrm{ZnO}$ NPs, thus indicating a progressive reduction of their crystallinity along with the size reduction induced through organosilane surface modification.

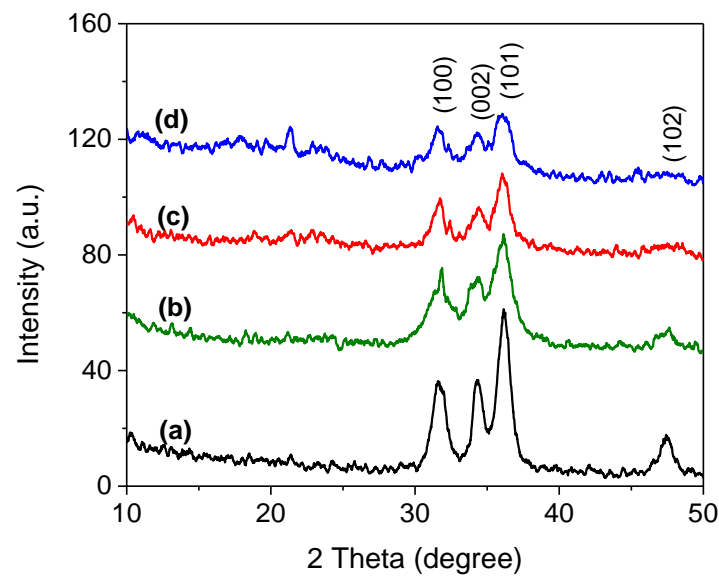

Figure 1. XRPD profiles of $\mathrm{ZnO}$ (a), $\mathrm{ZnO}-\mathrm{MPS}-2 \%$ (b), $\mathrm{ZnO}-\mathrm{MPS}-5 \%$ (c), and $\mathrm{ZnO}-\mathrm{MPS}-10 \%$ (d).

The average crystallite size of prepared ZnO NPs was estimated by applying the Debye-Scherrer's Eq. (1), and a progressive decrease of the crystallite size from $9.5 \mathrm{~nm}$ for $\mathrm{ZnO}$ to $7,6.5$ and $3 \mathrm{~nm}$ for $\mathrm{ZnO}$ MPS-2\%, ZnO-MPS-5\% and ZnO-MPS-10\%, respectively, was attained.

Particle size and morphology of $\mathrm{ZnO}$ samples were also studied by scanning electron microscopy (SEM) and their micrographs are given in Fig. 2. 



Figure 2. SEM images of $\mathrm{ZnO}(\mathrm{A}), \mathrm{ZnO}-\mathrm{MPS}-$ $2 \%$ (B), $\mathrm{ZnO}-\mathrm{MPS}-5 \%$ (C) and $\mathrm{ZnO}-\mathrm{MPS}-10 \%$ (D)

The SEM image of unmodified $\mathrm{ZnO}$ sample (Fig. 2A) shows that this materials consists of primary particles of $c a .29 \mathrm{~nm}$ with nearly spherical shape that are mostly organized into bigger aglomerates. Particles with similar morphology are also observed for all the organosilane-treated $\mathrm{ZnO}$ samples. In the case of $\mathrm{ZnO}$-MPS $2 \%$ (Fig. 2B), the primary particles have diameters of $c a .23 \mathrm{~nm}$ and are fused into bigger aglomerates, which in turn are fused into even bigger aggregates. The primary particles become smaller as the organosilane concentration increases, and thus sizes of $c a .11 \mathrm{~nm}$ for $\mathrm{ZnO}-\mathrm{MPS} 5 \%$ (Fig. 2C) and ca. $6 \mathrm{~nm}$ for $\mathrm{ZnO}$ MPS $10 \%$ (Fig. 2D) are attained.

\subsection{Photocatalytic activity}

Two series of experiments were carried out by exposing the methylene blue (MB) aqueous solutions containing the prepared $\mathrm{ZnO}$ NPs at two UV irradiation wavelengths, $254 \mathrm{~nm}$ and $365 \mathrm{~nm}$. In Fig. 3, the absorbance spectra of both MB solution and $\mathrm{ZnO}$ NPs based MB solutions, after exposure at $254 \mathrm{~nm}$ for one hour, are given. From this figure, it can be observed that the extent of photocatalytic degradation of $\mathrm{MB}$ is determined by the reduction of the absorbance of all $\mathrm{MB}$ solutions containing $\mathrm{ZnO}$ NPs (the maximum peak was observed at $\lambda_{\max }=665$ $\mathrm{nm}$ ), with a decreasing trend from unmodified $\mathrm{ZnO}$ to $\mathrm{ZnO}-\mathrm{MPS}-10 \%$. The values of their absorbance is comprised in a very narrow range, especially for $\mathrm{ZnO}$ NPs modified with $2 \%$ and 5\% MPS, whose absorbance spectra are completely overlapped. The decreased values of the absorbance is in direct correlation with the rate of discoloration, which increased as the nanoparticles size decreased.

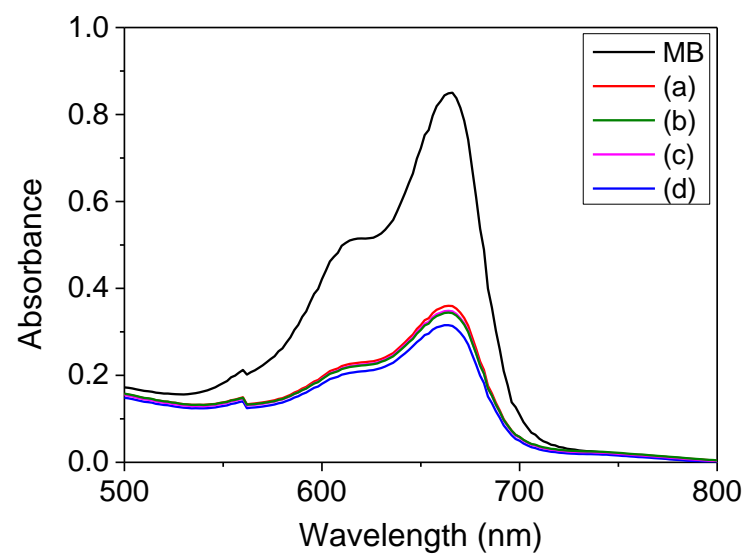

Figure 3. UV-Vis absorption spectra of methylene blue in the presence of $\mathrm{ZnO}$ (a), ZnO-MPS-2\% (b), ZnO-MPS-5\% (c) and ZnO-MPS-10\% (d), after UV irradiation at $254 \mathrm{~nm}$.

As indicated in Fig. 4, the photodegradation efficiency of all $\mathrm{ZnO}$ samples has greatly enhanced, though being comprised in a very narrow range, increasing from $58 \%$ in unmodified $\mathrm{ZnO}$ to $63 \%$ in $\mathrm{ZnO}-\mathrm{MPS}-10 \%$. Thus, the photocatalytic reaction rates of these nanoparticles could be enhanced by maneuvering their particles size to improve the electron transfer rates [33].

In Fig. 5, the absorbance spectra of both MB solution and $\mathrm{ZnO}$ NPs based MB solutions, after exposure at $365 \mathrm{~nm}$ for one hour, are given. From this figure, the extent of photocatalytic degradation of $\mathrm{MB}$ is evidenced by the reduction of the absorbance of all MB solutions containing ZnO NPs. Even in this case, the maximum peak was observed at $\lambda_{\max }=665 \mathrm{~nm}$. Unlike the first series of 
experiments, the variation trend of the absorbance values observed in the second series of experiments was opposite. As such, the absorbance values decreased from $\mathrm{ZnO}-\mathrm{MPS}-10 \%$ to unmodified $\mathrm{ZnO}$ NPs, and the rate of discoloration decreased as the nanoparticles size increased.

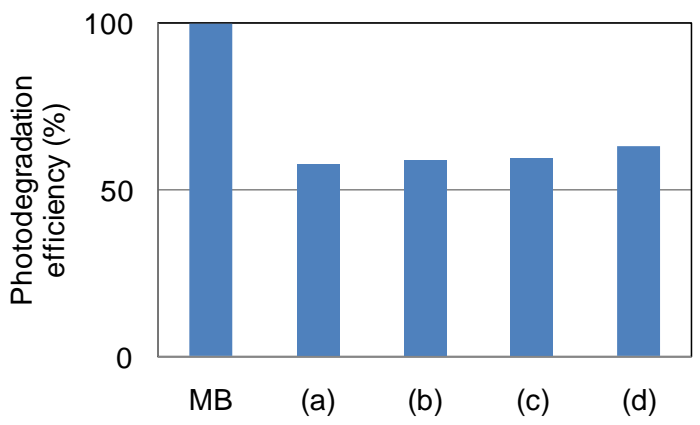

Figure 4. Photodegradation efficiency of $\mathrm{ZnO}$ (a), $\mathrm{ZnO}-\mathrm{MPS}-2 \%$ (b), ZnO-MPS-5\% (c) and $\mathrm{ZnO}-$ MPS-10\% (d), after UV exposure of MB-containing solutions at $254 \mathrm{~nm}$.

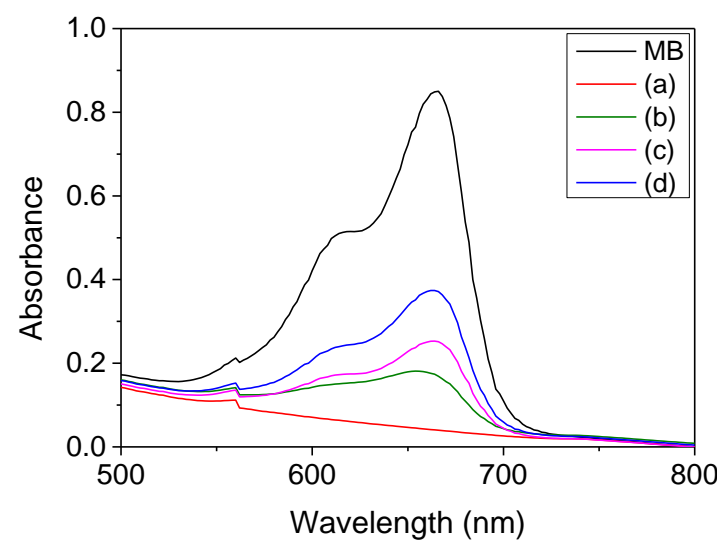

Figure 5. UV-Vis absorption spectra of methylene blue in the presence of $\mathrm{ZnO}$ (a), ZnO-MPS-2\% (b), $\mathrm{ZnO}-\mathrm{MPS}-5 \%$ (c) and $\mathrm{ZnO}-\mathrm{MPS}-10 \%$ (d), after UV irradiation at $365 \mathrm{~nm}$.

As indicated in Fig. 6, the photodegradation efficiency of all $\mathrm{ZnO}$ samples increased from $56 \%$ in the case of $\mathrm{ZnO}-\mathrm{MPS}-10 \%$ to $70 \%, 80 \%$ and $95 \%$ for $\mathrm{ZnO}-\mathrm{MPS}-5 \%$, ZnO-MPS-2\% and unmodified $\mathrm{ZnO}$, respectively. As a matter of fact, a complete discoloration of unmodified $\mathrm{ZnO}$ NPs based MB solution was observed (Fig. 7), thus highlighting the best photocatalytic performance exhibited by the unmodified $\mathrm{ZnO}$ NPs towards the degradation of MB molecules upon UV exposure at $365 \mathrm{~nm}$ for $1 \mathrm{~h}$. A comparable performance was also attained by Chiu et al. on two-dimensional $\mathrm{ZnO}$ nanopellets upon UV exposure at $254 \mathrm{~nm}$ for $6 \mathrm{~h}$ [34], and by Musat et al. on ZnO NPs with nanocrystallites size of $7 \mathrm{~nm}$ upon exposure at $210 \mathrm{~nm}$ for $1 \mathrm{~h} \mathrm{[35].}$

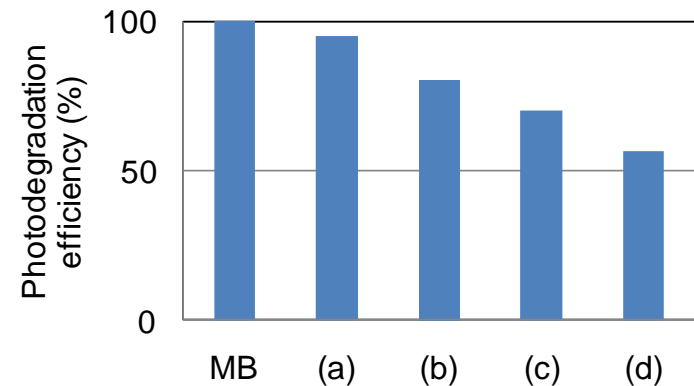

Figure 6. Photodegradation efficiency of $\mathrm{ZnO}$ (a), $\mathrm{ZnO}-\mathrm{MPS}-2 \%$ (b), ZnO-MPS-5\% (c) and $\mathrm{ZnO}-$ MPS-10\% (d), after UV exposure of MB-containing solutions at $365 \mathrm{~nm}$.

As far as the photocatalytic activity of ZnO NPs modified with MPS is concerned, the values obtained for the photodegradation efficiency are also significant, especially for $\mathrm{ZnO}$ samples modified with $2 \%$ and $5 \%$ MPS upon UV exposure at $365 \mathrm{~nm}$. To the best of our knowledge, no other report, where $\mathrm{ZnO}$ NPs were found to exhibit enhanced photodegradation efficiency after being modified with this type of organosilane surfactant, was found up to date. Instead, in only one report $\mathrm{ZnO}$ NPs modified with polystyrene were studied for the photocatalytic degradation of methyl orange, and for this case, the organic surfactant induced a significant decrease in the photodegradation efficiency in comparison with unmodified $\mathrm{ZnO}$ NPs which proved much more effective [36]. This fact allows us to state that only a limited number of organic surfactants are able to produce a positive influence on the photocatalytic performance in the modified ZnO NPs.

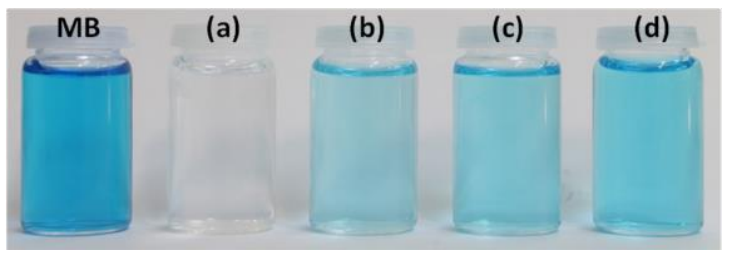

Figure. 7. Color of the methylene blue solution before UV irradiation (MB) and discoloration of MB solutions containing $\mathrm{ZnO}$ (a), ZnO-MPS-2\% (b), ZnO-MPS-5\% (c) and ZnO-MPS-10\% (d), after UV irradiation at $365 \mathrm{~nm}$.

The different behavior of this series of nanoparticles at the two UV exposure wavelengths of $254 \mathrm{~nm}$ and $365 \mathrm{~nm}$ could be explained not only on the basis of nanoparticles size, but also on the effect of chemical groups present in the structure of the organosilane surfactant. On the other hand, the energy corresponding to the wavelength of $254 \mathrm{~nm}$ is too high to be absorbed by the ZnO-MPS samples, making the organosilane shell, which surrounds the $\mathrm{ZnO}$ core [27], to act like a barrier against UV radiation. Consequently, the partial coverage of $\mathrm{ZnO}$ 
surface with this organosilane allows less generation of hydroxyl radicals for the oxidation of $\mathrm{MB}$ molecules, thus leading to lower photodegradation efficiency of MPS-modified $\mathrm{ZnO}$ samples. The energy corresponding to the wavelength of $365 \mathrm{~nm}$, instead, is sufficiently low to promote the absorption on behalf of the ZnO-MPS samples. In this case, the barrier effect of the organosilane shell is cancelled, thus allowing a better generation of hydroxyl radicals to oxidize much higher amount of $\mathrm{MB}$ molecules. These aspects, along with the photocatalytic mechanism related to such type of organosilane-modified $\mathrm{ZnO} \mathrm{NPs}$, will be developed in more detail in the near future study.

\section{Conclusions}

The photocatalytic performance of a series of ZnO NPs modified with the organosilane surfactant MPS was tested towards the degradation of MB at two UV exposure wavelengths. Modification of $\mathrm{ZnO}$ surface was found to have a great influence on its photocatalytic activity. The optimal condition for the photocatalytic degradation of $\mathrm{MB}$ using this series of $\mathrm{ZnO}$ NPs was their exposure at $365 \mathrm{~nm}$ for $1 \mathrm{~h}$. The best photocatalyst was the unmodified $\mathrm{ZnO}$, reaching a photodegradation efficiency of $95 \%$, followed by $\mathrm{ZnO}$ NPs modified with $2 \%$ MPS for which the photodegradation efficiency amounted to $80 \%$. These results are of great importance for solving, e.g., the issues of worldwide concern, such as quality drinking water, wastewater treatment and bacteria disinfection.

\section{Acknowledgments}

The work of Aurel Tăbăcaru has been funded by the Sectoral Operational Program Human Resources Development 2007-2013 of the Ministry of European Funds through the Financial Agreement POSDRU/159/1.5/S/132397. Prof. Rodica Dinica from the "Dunărea de Jos" University of Galati is gratefully acknowledged for helpful experimental assistance.

\section{References}

[1]. M.A. Hood, M. Mari, R. Muñoz-Espí, Materials 7, 4057 (2014).

[2]. J. Li and J.Z. Zhang, Coord. Chem. Rev. 253, 3015 (2009).

[3]. C.F. Klingshirn, B.K. Meyer, A. Waag, A. Hoffmann and J. Geurts, Zinc Oxide From Fundamental Properties Towards Novel Applications, Springer-Verlag, Berlin, 2010.

[4]. L. Qian, Y. Zheng, J. Xue and P.H. Holloway, Nature Photonics 5, 543 (2011).

[5]. U. Ozgur, Ya.I. Alivov, C. Liu, A. Teke, M.A. Reshchikov, S. Dogan, V. Avrutin, S.-J.Cho and H. Morkoc, J. Appl. Phys. 98, 041301 (2005)

[6]. J. Mawyin, Y. Shupyk, M. Wang, G. Poize, P. Atienzar, T. Ishwara, J.R. Durrant, J. Nelson, D. Kanehira, N. Yoshimoto, C. Martini, E. Shilova, P. Secondo, H. Brisset, F. Fages and J. Ackermann, J. Phys. Chem. C 115, 10881 (2011).

[7]. E. Fortunato, P. Barquinha and R. Martins, Adv. Mater. 24, 2945 (2012).

[8]. M. Karimi, J. Saydi, M. Mahmoodi, J. Seidi, M. Ezzati, S. Shamsi Anari and B. Ghasemian, J. Phys. Chem. Solid 74, 1392 (2013).

[9]. Y. Martynova, B.-H. Liu, M.E. McBriarty, I.M.N. Groot, M.J. Bedzyk, S. Shaikhutdinov and H.-J. Freund, J. Catal. 301, 227 (2013).

[10]. X. Tang, E.S.G. Choo, L. Li, J. Ding and J. Xue, Langmuir 25, 5271 (2009).

[11]. M. Busila, V. Musat, T. Textor and B. Mahltig, RSC Adv. 5, 21562 (2015)

[12]. D.M. Yebra, S. Kiil, C.E. Weinell and K. DamJohansen, Prog. Org. Coat. 56, 327 (2006).

[13]. M.R. Hoffmann, S.T. Martin, W. Choi and D.W. Bahnemann, Chem. Rev. 95, 69 (1995).

[14]. P. Periyat, S.C. Pillai, D.E. McCormack, J. Colreavy and S.J. Hinder, J. Phys. Chem. C 112, 7644 (2008).

[15]. S. Funk, B. Hokkanen, U. Burghaus, A. Ghicov and P. Schmuki, Nanoletters 7, 1091 (2007).

[16]. T. Zhang, T. Oyama, S. Horikoshi, J. Zhao, N. Serpone and H. Hidaka, Appl. Catal. B: Environ. 42, 13 (2003).

[17]. T. Zhang, L. You and Y. Zhang, Dyes Pigments 68, 95 (2006).

[18]. J. Emsley, Titanium. Nature's Building Blocks: An A-Z Guide to the Elements, Oxford University Press, Oxford, England, 2001.

[19]. S. Sakthivel, B. Neppolian, M.V. Shankar, B. Arabindoo, M. Palanichamy and V. Murugesan, Sol. Energy Mater. Sol. C 77, 65 (2003).

[20]. J.H. Sun, S.Y. Dong, Y.K. Wang and S.P. Sun, J. Hazard. Mater. 172, 1520 (2009).

[21]. P.V. Kamat, R. Huehn and R. Nicolaescu, J. Phys. Chem. B 106, 788 (2002).

[22]. S.C. Padmanabhan, S.C. Pillai, J. Colreavy, S. Balakrishnan, D.E. McCormack, T.S. Perova, S.J. Hinder and J.M. Kelly, Chem. Mater. 19, 4474 (2007).

[23]. J.M. Herrmann, H. Tahiri, Y. Ait-Ichou, G. Lassaletta, A.R. González-Elipe and A. Fernández, Appl. Catal. B: Environ. 13, 219 (1997).

[24]. K. Saoud, R. Alsoubaihi, N. Bensalah, T. Bora, M. Bertino, J. Dutta, Mater. Res. Bull. 63, 134 (2015). 
[25]. M. Ibanescu (Busila), V. Musat, T. Textor, V. Badilita, B. Mahltig, J. Alloys Compd. 610, 244 (2014).

[26]. G. Merga, L.C. Cass, D.M. Chipman and D. Meisel, J. Am. Chem. Soc. 130, 7067 (2008).

[27]. V. Musat, A. Tabacaru, B.S. Vasile and V.-A. Surdu, RSC Adv. 4, 63128 (2014).

[28]. A. Tabacaru, V. Musat, N. Tigau, B.S. Vasile and V.-A. Surdu, Appl. Surf. Sci., to be published.

[29]. A. Tabacaru, V. Musat, R.M. Dinica and C. Gheorghies, Rev. Chim. (Bucharest), to be published.

[30]. A.L. Patterson, Phys. Rev. 56, 972 (1939).

[31]. H.P. Klug and L.E. Alexander, X-ray diffraction procedures for polycrystalline and amorphous materials, Wiley, New York, 1974.
[32]. Powder Diffract. File, JCPDSB Internat. Centre Diffract. Data, PA 19073-3273, U.S.A. (2001).

[33]. K.J. Klabunde (Ed.), Nanoscale Materials in Chemistry, John Wiley \& Sons, Inc., USA, 2002.

[34]. W.S. Chiu, P.S. Khiew, M. Cloke, D. Isa, T.K. Tan, S. Radiman, R. Abd-Shukor, M.A. Abd. Hamid, N.M. Huang, H.N. Limd and C.H. Chia, Chem. Eng. J. 158, 345 (2010).

[35]. M. (Busila) Ibanescu, V. Musat, T. Textor, V. Badilita, B. Mahltig, The Annals of "Dunarea de Jos" of Galati, Fascicle IX, Metallurgy and Materials Science 2, 54 (2013).

[36]. R.Y. Hong, J.H. Li, L.L. Chen, D.Q. Liu, H.Z. Li, Y. Zheng and J. Ding, Powder Technology 189, 426 (2009).

Received: 17 September 2015 Received in revised form: 21 September 2015

Accepted: 21 September 2015 